\title{
Which articles do we prefer to publish?
}

\author{
Hangi yazıları yayımlamayı tercih ediyoruz? \\ O. Şahap Atik, MD \\ Department of Orthopedics and Traumatology, Medical Faculty of Gazi University, Ankara, Turkey
}

First of all, we prefer original research and data like all academic journals. For this reason, the research must start with an original research question or hypotheses. ${ }^{[1,2]}$ The manuscript must give a new message. The message must be important, too.

Appropriate study design is crucial for obtaining valid and scientific results. The methods section should explain the steps taken to produce the results. ${ }^{[2]}$ It should contain adequate details for other researchers to replicate the study. ${ }^{[1]}$

Avoid reporting data not directly related to the hypotheses or questions..$^{[1]}$ The manuscript must be long enough. Too many words can be distracting for the reader.
The researchers must point out the weaknesses of study in the discussion section of the manuscript.

The manuscript must be appropriate for our journal's aims and scope. ${ }^{[3]}$ Finally, it must be written exactly according to the format of our journal in terms of shape and content.

\section{REFERENCES}

1. Brand RA. Writing for clinical orthopaedics and related research. Clin Orthop Relat Res 2008;466:239-47.

2. Atik OS. How to write a scientific article?. [Article in Turkish] Eklem Hastalik Cerrahisi 2012;23:60.

3. Atik OŞ. Are all case reports worth publishing? Eklem Hastalik Cerrahisi 2016;27:61. 